\title{
La COVID-19 y las oportunidades de cooperación internacional en salud
}

\author{
COVID-19 and opportunities for international \\ cooperation in health
}

\author{
COVID-19 e as oportunidades de cooperação \\ internacional em saúde
}

Paulo Marchiori Buss 1

Sebastián Tobar 1

doi: 10.1590/0102-311X00066920

El 11 de marzo de 2020, la Organización Mundial de la Salud (OMS) declaró la enfermedad COVID-19, causada por el nuevo coronavirus SARS-CoV-2, como una pandemia. En el momento de escribir este artículo, se registran más de 1,3 millón de infectados, con más de 80 mil muertos (letalidad de 5,9\%), en todos los países del mundo. En las Américas, son cerca de 400 mil casos y 12 mil muertes, con los Estados Unidos representando cerca de un 85\%, tanto de los casos, como de las muertes del continente. En Brasil, el país más afectado de América del Sur, son cerca de 14 mil casos y más de 700 muertos (letalidad del 5\%).

La pandemia ha demostrado ser un problema que puede impactar profundamente la economía global: se han evaporado trillones de dólares de las bolsas de valores de todo el mundo, antes que cerraran sus puertas para evitar el colapso absoluto, sea porque sus operadores cayesen enfermos, sea por la caída de sus activos financieros; millones de personas perdieron sus empleos, por lo menos temporalmente, y otros tantos trabajadores informales, excluidos de los esquemas de protección social, fueron abocados -por gobiernos omisos- a una trágica elección: o salen de sus casas para ganar el pan y se exponen al virus o se quedan en el aislamiento social y mueren de hambre.

Los gobiernos tuvieron que abrir sus arcas y gastar en servicios de salud, en ayuda económica a las empresas y a los trabajadores (en ese orden) o ver deteriorarse todavía más la situación social y sanitaria. El G20 prometió inyectar USD 4,8 trillones en la economía global; los Estados Unidos destinaron USD 2,3 trillones para estímulos a la economía nacional, pero no ha invertido nada para la ayuda internacional o para la salud global, en la cual el país ya ha sido uno de los campeones; en Brasil, los números anunciados por el gobierno federal son imprecisos, pero desde hace mucho un Sistema Único de Salud (SUS) desguazado tiene que lidiar con un perfil complejo de problemas de salud, la mayoría de ellos determinado o condicionado por la inmensa desigualdad socioeconómica vigente.

En un escenario de mayor vulnerabilidad, donde las enfermedades van más allá de las fronteras nacionales de los países, globalizándose los riesgos para la salud, el nivel subregional, vinculado a iniciativas de integración, presenta grandes oportunidades para la cooperación en salud.

Entre 2008 y 2019, América del Sur fue un ejemplo de cooperación en salud, durante la existencia de la Unión de Naciones Suramericanas (UNASUR). Como parte de la estructura más alta de la gobernanza de esta iniciativa de integración regional, se contaba con el Consejo de Salud Sudamericano integrado por los 12 Ministros de Salud de la región. En esa época, el enfrentamiento colectivo de
1 Centro de Relações Internacionais em Saúde, Fundação Oswaldo Cruz, Rio de Janeiro, Brasil.

Correspondencia P. M. Buss Centro de Relações Internacionais em Saúde, Fundação Oswaldo Cruz. Av. Brasil 4365, Rio de Janeiro, RJ 21045-900, Brasil. paulo.buss@fiocruz.br 
los países a la pandemia de influenza de H1N1, epidemias de dengue y la organización de acciones comunes contra otras enfermedades transmisibles emergentes y reemergentes, la preparación colectiva para la eventual llegada del virus Ébola, fueron dirigidos por el Consejo, apoyado por los Jefes de Estado e implementado por centenas de técnicos de los ministerios y sistemas de salud de los Estados miembros.

La implosión de UNASUR, o sea el rechazo al multilateralismo regional, liquidó este mecanismo estable que funcionó formalmente durante cerca de diez años en la región.

Restaurar estos mecanismos políticos y técnicos es fundamental para el enfrentamiento a la epidemia del nuevo coronavirus, así como para los nuevos posibles desafíos de salud de interés internacional, pues simplemente cerrar fronteras no es la solución. Sudamérica tiene cerca de 48 fronteras a lo largo de 17 mil kilómetros. La vida cotidiana de la población de las áreas fronterizas siempre transcurrió con beneficios mutuos e intensa cooperación para enfrentar conjuntamente problemas comunes.

Los Ministerios de Salud de la región están realizando consultas entre ellos, pero es ventajoso institucionalizar tales relaciones en el más alto nivel e intensificar las consultas y la ayuda mutua, con el fin de que sean implementadas medidas técnicas racionales de vigilancia de salud de fronteras, que dependen de los 12 países con fronteras e historias de amistad compartida, con grandes beneficios para todos.

"El tiempo para desacelerar la propagación de la COVID-19 se está acortando en las Américas, los países deben actuar ahora (...). Este virus no ha sido, ni será detenido, por las fronteras trazadas en los mapas” 1, así lo afirmó la Directora de la Organización Panamericana de la Salud (OPS), Carissa Etienne, quien llamó a tomar medidas urgentes para garantizar el espacio hospitalario, las camas, el personal de salud y el equipo de protección del personal de salud, necesarios para hacer frente a la creciente afluencia de personas con la enfermedad.

Es posible identificar algunas líneas de trabajo que, sin duda, aportarían a la toma de decisiones de los países, en relación a la pandemia por COVID-19, así como de otras nuevas enfermedades, inclusive virales epidémicas, que amenazan el mundo y la región:

(a) Intercambio de datos y seguimientos de la epidemia, construyendo curvas comparativas de evolución de la COVID-19 en los países y apropiándose de medidas y soluciones adoptadas en varias dimensiones (social, sanitaria y clínica) para el enfrentamiento de la epidemia. Intercambio de experiencias y lecciones aprendidas.

(b) Búsqueda de información para el diagnóstico, vigilancia, control y prevención de la COVID-19, identificando las que están basadas en evidencias científicas, que puedan apoyar y alimentar los procesos de formulación de políticas (policy making) y toma de decisiones (decision making) y el descarte de informaciones falsas (fake news).

(c) Creación de una red regional de laboratorios para el diagnóstico de la COVID-19 y otros virus, con un programa que garantice la calidad del diagnóstico de los laboratorios en la región.

(d) Adopción de incentivos para la investigación, innovación tecnológica y producción de tecnologías sanitarias apropiadas para la COVID-19 (equipamientos médicos, respiradores, reactivos, equipos de protección etc.), integrando esfuerzos y promoviendo economías de escala y capacidades de los países promoviendo la cooperación.

(e) Adopción de mecanismos para la negociación y compra conjunta de insumos estratégicos para enfrentar la pandemia.

(f) Construcción de fondos regionales para el soporte financiero de emergencia frente a la pandemia y otras contingencias que afecten la salud pública.

(g) Movilizar las redes estructuradoras de instituciones suramericanas existentes (institutos nacionales de salud pública; escuelas de salud pública; y escuelas técnicas de salud) para la organización de investigaciones compartidas, formación de recursos humanos y asistencia-cooperación técnica oportunas para la situación.

La Dra. Etienne 1 también ha afirmado que "sin evidencia sólida sobre los tratamientos efectivos y sin vacunas disponibles, el distanciamiento social y otras medidas preventivas enérgicas siguen siendo nuestra mejor apuesta para prevenir las consecuencias más graves de la pandemia de COVID-19 en nuestra región. Este momento exige que haya un liderazgo audaz y compasivo".

La integración subregional tendría que estimular la construcción de inteligencia sanitaria para la vigilancia y la definición de medidas que sirvan para la supresión o mitigación de la COVID-19, asî 
como para la emergencia de nuevos virus con potencial pandémico. Por otro lado, no tiene sentido excluir un territorio por ideología, como por ejemplo Venezuela o cualquier otro país. La pandemia afecta a todos, sin distinción; o todos o nadie.

La formalización e institucionalización de estas relaciones intergubernamentales en el más alto nivel abrirá camino e incentivará una vital cooperación entre universidades, institutos de investigación, escuelas de salud pública y graduación en las formaciones de salud, propiciando establecer la capacitación de recursos humanos y el desarrollo de proyectos de investigación y desarrollo tecnológico, que respondan a las necesidades comunes de los países de nuestra región, para el combate a la epidemia.

Esta cooperación en la subregión vendría a reforzar la acción continental de la OPS, que reúne todos los países de la región de las Américas, en una importante iniciativa más en el campo de la diplomacia de salud regional.

Resta preguntarse, si el Foro para el Progreso de América del Sur (PROSUR), impulsado por gobiernos neoconservadores en sustitución de UNASUR, pondrá la salud por encima de los intereses económicos, recreando las oportunidades de cooperación Sur-Sur en salud que ofrece el nivel subregional para hacer frente al desafío de la COVID-19. Si no se construye esta inteligencia epidemiológica a nivel subregional, mediante la cooperación en salud, quedaríamos vulnerables frente al nuevo coronavirus, así como ante otras enfermedades con potencial pandémico.

En este sentido, el Caribe ha dado un importante paso con la creación de la Agencia Caribeña de Salud Pública (CARPHA) 2, mientras que regiones como África se han decidido por la creación de un Centro de Control de Enfermedades (CDC/AFRO) 3 constituyendo, en ambos casos, importantes soluciones organizativas y de inteligencia sanitaria regional para enfrentar la pandemia. Cómo puede Suramérica aprender de las iniciativas internacionales y quizá seguir un camino semejante?

Finalmente, si las comunicaciones recientes del Fondo Monetario Internacional (FMI) y el Banco Mundial, que dispondrían de USD 1 trillón y USD 14 billones, respectivamente, para préstamos blandos a los países más vulnerables y frágiles son sinceras, y se hicieran realidad, los países de la región deberían buscar conjuntamente recursos económicos críticos a coste cero en estas instituciones para enfrentar la pandemia. En este sentido, podría ser la oportunidad para hacer de esta propuesta y estos mecanismos de integración en salud un verdadero "bien público regional".

\section{Colaboradores}

Los autores contribuyeron igualmente en la elaboración del artículo.

\section{Referencias}

1. Etienne C. El tiempo para desacelerar la propagación de la COVID-19 se está acortando en las Américas, los países deben actuar ahora. https:// www.paho.org/hq/index.php?option $=$ com $_{-}$ content \&view $=$ article \&id = 15762:el-tiempopara-desacelerar-la-propagacion-de-la-covid19-se-esta-acortando-en-las-americas-los-pai ses-deben-actuar-ahora\&catid=740\&lang =es $\&$ Itemid=1926 (accedido el 01/Abr/2020).

2. Caribbean Public Health Agency. Emergency response and disaster preparedness. https:// carpha.org/What-We-Do/Emergency-Re sponse (accedido el 01/Abr/2020).

3. Africa Centres for Disease Control and Prevention. Emergency preparedness and response. https://africacdc.org/programme/emergencypreparedness-and-response/ (accedido el 01/ Abr/2020).

Recibido el 02/Abr/2020

Aprobado el 03/Abr/2020 